Document downloaded from:

http://hdl.handle.net/10251/146177

This paper must be cited as:

Salaberria, A.; Teruel Juanes, R.; Badia, J.; Fernandes, S.; Sáenz De Juano-Arbona, V.; Labidi, J.; Ribes-Greus, A. (20-1). Influence of chitin nanocrystals on the dielectric behaviour and conductivity of chitosan-based bionanocomposites. Composites Science and Technology. 167:323-330. https://doi.org/10.1016/j.compscitech.2018.08.019

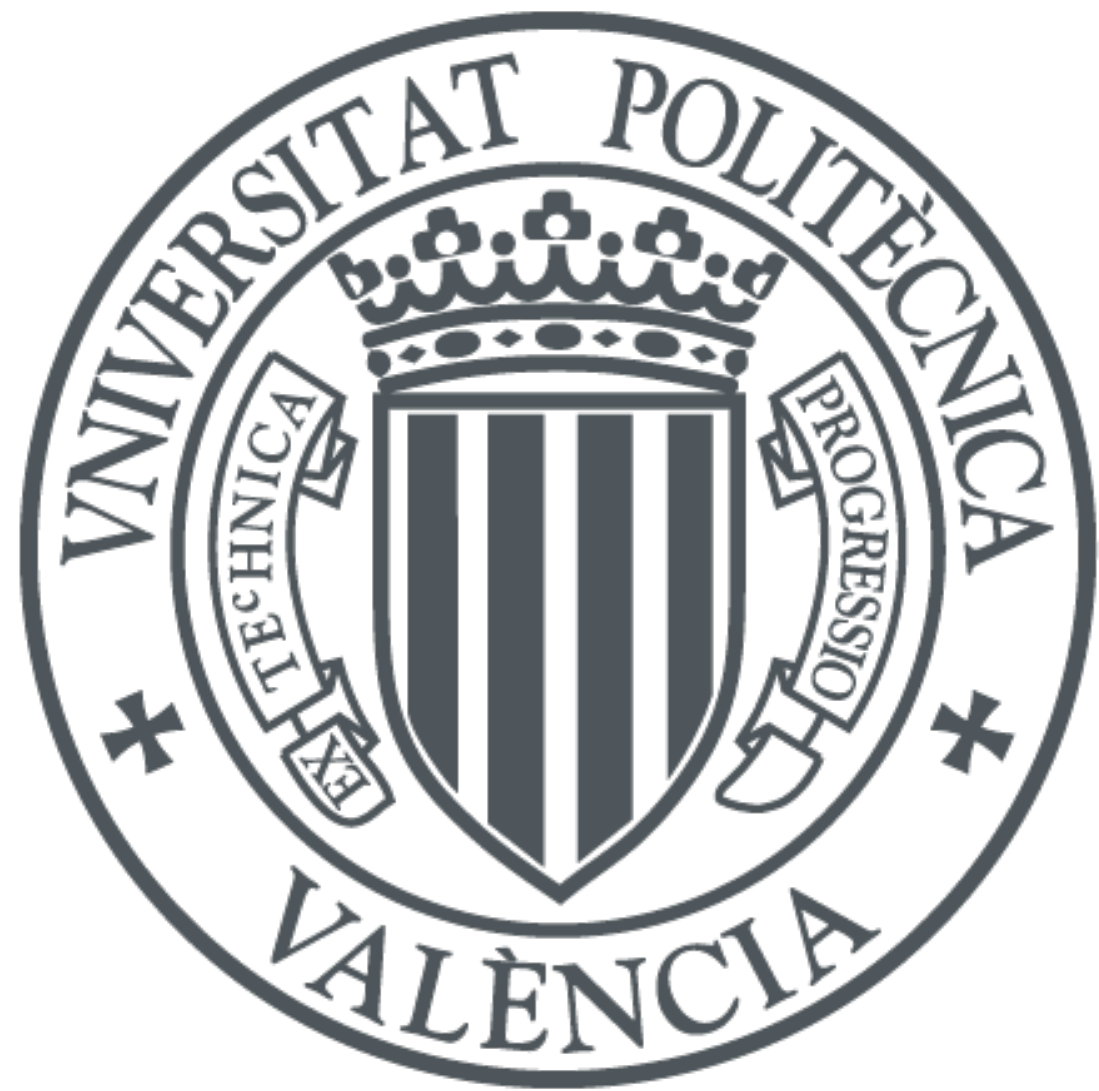

The final publication is available at

https://doi.org/10.1016/j.compscitech.2018.08.019

Copyright Elsevier

Additional Information 
A.M. Salaberría1, R. Teruel-Juanes2, JD.Badia2,3, S.C.M. Fernandes1, V. Sáenz de Juano-Arbona2, J. Labidi1, A. Ribes-Greus. Influence of chitin nanocrystals on the dielectric behaviour and conductivity of chitosan-based bionanocomposites. Composites Science and Technology 2018; 167:323-330

\title{
INFLUENCE OF CHITIN NANOCRYSTALS ON THE DIELECTRIC BEHAVIOUR AND CONDUCTIVITY OF CHITOSAN-BASED BIONANOCOMPOSITES
}

A.M. Salaberría ${ }^{1}$, R. Teruel-Juanes ${ }^{2}$, JD.Badia ${ }^{2,3}$, S.C.M. Fernandes ${ }^{1}$, V. Sáenz de Juano-

\author{
Arbona $^{2}$, J. Labidi ${ }^{1}$, A. Ribes-Greus ${ }^{2, *}$
}

This is an open-access version, according to http://www.sherpa.ac.uk/romeo/issn/0266-3538/es/

Full text available at: https://www.sciencedirect.com/science/article/pii/S0266353818304652

DOI: $\underline{\text { https://doi.org/10.1016/j.compscitech.2018.08.019 }}$

Please, cite it as:

A.M. Salaberría1, R. Teruel-Juanes2, JD.Badia2,3, S.C.M. Fernandes1, V. Sáenz de Juano-Arbona2, J. Labidi1,

A. Ribes-Greus. Influence of chitin nanocrystals on the dielectric behaviour and conductivity of chitosan-based bionanocomposites. Composites Science and Technology 2018; 167:323-330

${ }^{1}$ Biorefinery Processes Research Group, Department of Chemical and Environmental Engineering, Faculty of Engineering, University of the Basque Country (UPV/EHU). Plaza Europa 1, 20018 Donostia-San Sebastian, Spain

${ }^{2}$ Instituto de Tecnología de los Materiales (ITM), Universitat Politècnica de València (UPV). Camí de Vera, s/n, 46022, València, Spain

${ }^{3}$ Departament d'Enginyeria Química, Escola Tècnica Superior d' Enginyeria, Universitat de València (UV). Av de les Universitats, s/n, 46100 Burjassot, València, Spain

*Corresponding author: A. Ribes-Greus aribes@ter.upv.es

$-1-$ 
A.M. Salaberría1, R. Teruel-Juanes2, JD.Badia2,3, S.C.M. Fernandes1, V. Sáenz de Juano-Arbona2, J. Labidi1, A. Ribes-Greus. Influence of chitin nanocrystals on the dielectric behaviour and conductivity of chitosan-based bionanocomposites. Composites Science and Technology 2018; 167:323-330

\title{
INFLUENCE OF CHITIN NANOCRYSTALS ON THE DIELECTRIC BEHAVIOUR AND CONDUCTIVITY OF CHITOSAN-BASED BIONANOCOMPOSITES
}

\author{
A.M. Salaberría, R. Teruel-Juanes, JD.Badia, S.C.M. Fernandes, V. Sáenz de Juano-Arbona, \\ J. Labidi, A. Ribes-Greus
}

\begin{abstract}
A series of bionanocomposite films based on chitosan, reinforced with chitin nanocrystals, were developed, and assessed in terms of dielectric behavior and conductivity by using an experimental methodology that allows avoiding the conductivity contribution and the exclusion of contact and interfacial polarization effects. The dielectric relaxations at low and high frequency and temperatures were modeled by Havriliak-Negami functions. Below the glass transition temperature $(\mathrm{Tg})$, the $\gamma$ and $\beta$ relaxations were observed, which were related to intramolecular and non-cooperative segmental movements. At higher temperatures, an intermolecular and cooperative macromolecular movement, related to the glass transition, gave rise to $\alpha$-relaxation. In addition, two over-Tg $\rho_{I}$ and $\rho_{I I}$ relaxations were found, which were related to the displacement of dipoles in the disordered structure of bionanocomposites. The addition of chitin nanocrystals did not affect the apparent activation energy $E a$ of the $\gamma$ relaxation. However, it decreased the $E a$ of the $\beta$-relaxation and increased the free volume at temperatures in the vicinities of the $\alpha$-relaxation. Finally, the electric conductivity of the bionanocomposites was lower than that of neat chitosan and chitin due to the interaction between the $-\mathrm{OH}$ and $-\mathrm{NH}_{2}$ groups that reduced the ionic mobility, along with the increase of free volume, with the subsequent separation of phases.
\end{abstract}

\section{Keywords}

Bionanocomposites; Material testing; Dielectric thermal analysis (DETA); Chitosan; Chitin nanocrystals;

-2 - 
A.M. Salaberría1, R. Teruel-Juanes2, JD.Badia2,3, S.C.M. Fernandes1, V. Sáenz de Juano-Arbona2, J. Labidi1, A. Ribes-Greus. Influence of chitin nanocrystals on the dielectric behaviour and conductivity of chitosan-based bionanocomposites. Composites Science and Technology 2018; 167:323-330

\section{Introduction}

The biomass-derived materials are suitable for their use in many applications as a consequence of their biodegradability properties, biocompatibility, high availability and low cost, which makes them interesting for many industries. Materials from natural resources are hence developed in order to replace the petroleum-based ones by means of using products such as cellulose, starch, lignin, chitosan, chitin, among many other biopolymers, a mixture of these and composites with the aim of optimizing the long-term properties of the final material [1].

Within biomass polymers, chitin can be found in different living systems as crustacean shells, insect cuticles and cell walls of fungi, yeast and green algae [2]. This polymer, considered the second most abundant biopolymer on earth after cellulose, is composed of $\mathrm{N}$-acetyl-2-amido2-deoxy-D-glucose units linked by $\beta(1-4)$ bonds [3], [4]. Chitin nanostructures, obtained by chemical or mechanical treatments, are increasingly considered as suitable building blocks for the design of functional bionanocomposite materials, owing to their nanosized dimensions and unique rod-like or fibrous structure. Their unique properties - such as their extremely small size, low density, chemical stability, biological activity, and non-cytotoxicity-, make them excellent candidates for use in extensive applications [5]-[10].

Chitosan is the major and simplest chitin derivative, also with a high-molecular-weight linear polymer obtained by deacetylation of chitin. While chitin lacks of solubility in the most common solvents, the advantage of chitosan is its capacity to be dissolved in diluted aqueous solutions with $\mathrm{pH}<6.5$ [4]. In this sense, it has been blended with polymers such as poly(acrylic acid)[11], poly(vinylidene fluoride) [12] or poly(vynily alcohol) [13], as well as composited with fillers such as montmorillonite [14], carbon nanotubes [15], nanosilica [16], silver triflate [17], sodium triflate or alumnia [18].

$-3-$ 
A.M. Salaberría1, R. Teruel-Juanes2, JD.Badia2,3, S.C.M. Fernandes1, V. Sáenz de Juano-Arbona2, J. Labidi1, A. Ribes-Greus. Influence of chitin nanocrystals on the dielectric behaviour and conductivity of chitosan-based bionanocomposites. Composites Science and Technology 2018; 167:323-330

The design of biocomposites based on chitin and chitosan therefore represent a unique resource.

On the one hand, matrixes, fillers and biocomposites could be fabricated at the same place, with low environmental impact due to transport of raw materials. On the other hand, their residues could be easily managed without the usual difficulties of sorting or dismantling, since they have the same chemical nature. As a whole, the chitosan/chitin bionanocomposites can be ecodesigned from a cradle-to-cradle perspective [19], [20]. In this line, the preparation of specific bionanocomposites based on chitosan matrix reinforced with chitin nanocrystals and whiskers has been proposed [21]-[23]. A general improvement of the thermal stability, mechanical stiffness and antifungal activity of the biocomposites has been shown as a function of the presence of chitin nanocrystals [23].

Chitin-based materials are useful to prepare scaffolds, hydrogels and wound dressings, as adsorbents in industry, water purification, for protein immobilization, transformation of bacteria by exogenous genes, stabilization of oil-in-water emulsion and nematic gels, formation of $\mathrm{CaCO}_{3} /$ chitin-whisker hybrids and as carbon precursors [24]. In the field of composites, chitin nanocrystals and nanofibres have been reported to reinforce biocomposites of different matrixes such as poly(lactic acid) [25]-[27], thermoplastic starch [28], chitosan [23] or carrageenan [29] and as poly(vinyl alcohol) [30] among other. The use of chitin and chitosan actually stand up as a promising bioplastic alternative within the tendency of eco-design of materials [31]. There is a challenging area of innovation to the use of these bio-nanocomposites as in packaging for smart applications or, in the field of low temperature direct alcohol fuel cells, the preparation of membranes as polyelectrolyte. Among its advantages, it is worth mentioning its low-cost and eco-friendly nature; its hydrophilicity to perform at high temperatures and low relative humidity conditions; low permeability to alcohol molecules; and 
A.M. Salaberría1, R. Teruel-Juanes2, JD.Badia2,3, S.C.M. Fernandes1, V. Sáenz de Juano-Arbona2, J. Labidi1, A. Ribes-Greus. Influence of chitin nanocrystals on the dielectric behaviour and conductivity of chitosan-based bionanocomposites. Composites Science and Technology $2018 ; 167: 323-330$

high capacity of functionalisation, due to the chemical $-\mathrm{OH}$ and $-\mathrm{NH}_{2}$ groups present in its structure [31]. For these applications, an exhaustive characterization of dielectric and conductive properties is necessary during the design of these materials [32] .

Concerning the identification of dielectric relaxations, Viciosa et al analysed the macromolecular motions of wet and annealed chitosan by dielectric spectroscopy and found two Arrhenius-like $\beta$-relaxation, related to the interaction of $-\mathrm{NH}_{2}$ with water and the migration of conductive species, in an increasing temperature order [33]. These analyses were performed without a conductive barrier and the molecular relaxation masked by the conductive deviation could not be observed. Gonzalez-Campos et al proposed a mathematical methodology to suppress the contribution of the direct current (DC) conductivity and interfacial polarisation effects, and found in addition a VFTH-like $\alpha$-relaxation, correlated with the glass-rubber relaxation [34]. In the present work, a methodology to suppress the masking effect of the DC conductivity is carried out experimentally in the sample electrode assembly, which permits a deeper identification of dielectric relaxations. Thus, the focus of the present work was to correlate the relative amount of chitosan and chitin nanocrystals in the bionanocomposites in terms of dielectric and conductive properties. This study might contribute to optimise the knowledge about the success of chitin nanocrystals in the elaboration of proper bionanocomposites for a broad range of applications. 
A.M. Salaberría1, R. Teruel-Juanes2, JD.Badia2,3, S.C.M. Fernandes1, V. Sáenz de Juano-Arbona2, J. Labidi1, A. Ribes-Greus. Influence of chitin nanocrystals on the dielectric behaviour and conductivity of chitosan-based bionanocomposites. Composites Science and Technology 2018; 167:323-330

\section{Experimental procedure}

\subsection{Materials}

The bionanocomposite materials studied in this work was elaborated using Cervimunida Johni lobster as raw material for the extraction of chitin $(\mathrm{CHNC}, \mathrm{DA}=95 \pm 3 \%)$ and chitosan $(\mathrm{CS}$, $\mathrm{DA}=10 \pm 3 \%)$ materials. Chitosan-chitin nanocrystals (CS/CHNC) bionanocomposite films were prepared by solvent/evaporation technique. First $1 \% \mathrm{CS}$ solutions in acetic acid were prepared and filtered to eliminate any residues of chitosan powder. Then, three different amounts of CHNC were added in each solution and stirred during $30 \mathrm{~min}$ at $20.000 \mathrm{rpm}$ until homogeneous mixture, as reported in a previous work [23]. The bionanocomposites were labelled according to the CS:CHNC proportion, as follows: CS/CHNC0.5 for a 1:0.5 (33.33\% CHNC), CS/CHNC1 for 1:1(50\% CHNC) and CS/CHNCS for a 1:2(66.66\% CHNC). The formulations were poured into acrylic plates and the solvent was evaporated in a ventilated oven over night at $30^{\circ} \mathrm{C}$. All films were kept in a desiccator containing allochroic silica gel at room temperature for 1 week prior to any test.

\subsection{Dielectric and conductivity measurements}

The dielectric spectra (DS) of the samples were obtained using an Alpha mainframe frequency analyser in conjunction with an active cell (Concept 40, Novocontrol Technologies BmgH \& Co. Kc, Hundsangen, Germany). The sample electrode assembly (SEA) consisted of two stainless steel electrodes filled with the neat polymers and bionanocomposites. The methodology to prepare the SEA was directly placed in the cell a sandwich with a Teflon ${ }^{\mathrm{TM}}$ film of $(132 \mu \mathrm{m}$ thick) inserted as blocking layer between the sample and one electrode. The sample/Teflon ${ }^{\mathrm{TM}}$ sandwich is a Maxwell-Wagner-Sillars [37]-[39] layer capacitor, which 
A.M. Salaberría1, R. Teruel-Juanes2, JD.Badia2,3, S.C.M. Fernandes1, V. Sáenz de Juano-Arbona2, J. Labidi1, A. Ribes-Greus. Influence of chitin nanocrystals on the dielectric behaviour and conductivity of chitosan-based bionanocomposites. Composites Science and Technology 2018; 167:323-330

suppresses the direct current and avoids at low temperatures the dipole motion and the charge accumulation at the electrode interface [40]-[42]. It has been found that the dielectric response of the Teflon ${ }^{\mathrm{TM}}$ film is approximately 100 times less than the response of the studied bionanocomposites.

The diameters of the electrodes were $20 \mathrm{~mm}$ and the thickness was kept around $300 \mu \mathrm{m}$. The relative response was measured under isothermal conditions in the frequency range $f=10^{-2}$ $10^{6} \mathrm{~Hz}$, at temperatures of $-150^{\circ} \mathrm{C}$ to above melt temperature, controlled by the Quatro system (Novocontrol Technologies, Germany) by increasing steps of $10^{\circ} \mathrm{C}$ under inert nitrogen atmosphere and using liquid nitrogen as coolant.

The complex conductivity was analyzed by means of the same experimental set with a sample electrode assembly (SEA) consisting of two stainless steel electrodes filled with the neat polymers and bionanocomposites without Teflon ${ }^{\mathrm{TM}}$, at a frequency range of $\mathrm{f}=10^{-2}-10^{7} \mathrm{~Hz}$ under isothermal conditions at temperature of $298 \mathrm{~K}$ under inert nitrogen atmosphere.

\subsection{Thermal properties}

The thermogravimetric and calorimetric properties were carried out by means of a TGA/SDTA 851 and a DSC822 ${ }^{\mathrm{e}}$ Mettler Toledo instruments, respectively. The thermogravimetric scans were performed heating at a constant rate of $10{ }^{\circ} \mathrm{C} \cdot \mathrm{min}^{-1}$ from $25^{\circ} \mathrm{C}$ to $900{ }^{\circ} \mathrm{C}$ under a nitrogen atmosphere of $20 \mathrm{~mL} \cdot \mathrm{min}^{-1}$. The calorimetric first and second heating scan were performed in a semi hermetic-pan from -50 to $200{ }^{\circ} \mathrm{C}$ with a heating rate of $5{ }^{\circ} \mathrm{C} \cdot \mathrm{min}^{-1}$ under a nitrogen atmosphere. 
A.M. Salaberría1, R. Teruel-Juanes2, JD.Badia2,3, S.C.M. Fernandes1, V. Sáenz de Juano-Arbona2, J. Labidi1, A. Ribes-Greus. Influence of chitin nanocrystals on the dielectric behaviour and conductivity of chitosan-based bionanocomposites. Composites Science and Technology 2018; 167:323-330

\subsection{Structural analysis}

The crystallinity index was measured from the X-ray diffraction patterns obtained with a Philips Pert Pro automatic diffractometer using $\mathrm{Cu}-\mathrm{K} \alpha$ radiation (operating at $40 \mathrm{kV}$ and $40 \mathrm{~mA}$ ) over the angular range of $5-70^{\circ} 2 \theta($ step size $=0.04$ and time per step $=353 \mathrm{~s})$ at room temperature. The crystallinity index of nanocomposite films were calculated using equation 1

$$
\text { C.I. }(\%)=\left[\left(I_{110-} I_{a m}\right) / I_{110}\right] X 100 \quad(E q .1)
$$

, where $\mathrm{I}_{110}$ is the maximum intensity (arbitrary units) of the 110 crystallographic plane and $\mathrm{I}_{\mathrm{am}}$ is the amorphous portion diffraction, which usually is found about $2 \theta=12.5^{\circ}-13.5^{\circ}$. 
A.M. Salaberría1, R. Teruel-Juanes2, JD.Badia2,3, S.C.M. Fernandes1, V. Sáenz de Juano-Arbona2, J. Labidi1, A. Ribes-Greus. Influence of chitin nanocrystals on the dielectric behaviour and conductivity of chitosan-based bionanocomposites. Composites Science and Technology $2018 ; 167: 323-330$

\section{Results and Discussion}

\subsection{Phenomenological description of dielectric relaxations}

The dielectric behavior of chitosan CS, chitin nanocrystals CHNC and the chitosan/chitin CS/CHNC bionanocomposites are assessed in a large range of temperatures and frequencies. Dielectric Thermal Analysis (DETA) is of great importance to test the segmental rearrangements and dynamic fragility of polymers [43]-[47], which modifications are not perceptible by other macroscopic techniques. A particular experimental methodology was applied to obtain an accurate dielectric spectrum of these samples, without being affected by interfacial polarization effects nor by the conductivity contribution. Thus, the dielectric spectrum was measured without mathematically removing the term of the conductivity. The analysis is conducted essentially through loss tangent $(\tan \delta)$ and the complex dielectric permeability $\varepsilon^{*}=\varepsilon^{\prime}-i \varepsilon^{\prime}$, taking into account the real $\left(\varepsilon^{\prime}\right)$ and imaginary ( $\left.\varepsilon^{\prime \prime}\right)$ parts.

Figure shows the three-dimensional dielectric spectrum of chitosan CS, chitin nanocrystals CHNC and their bionanocomposites in terms of the loss tangent $\tan \delta$.

Figure shows the isochronal loss tan $\delta$ curves. The dielectric spectra of all samples exhibited, in an increasing temperature order, $\gamma$ and $\beta$ relaxations in the glassy state, which are characteristic local modes of mobility of the side groups. At higher temperatures, a complex relaxation zone in the rubber state was observed which were labelled as $\alpha, \rho_{\mathrm{I}}$ and $\rho_{\mathrm{II}}$ relaxations. The first was related to the glass-rubber relaxation (i.e. glass transition) and the latter to displacement of dipoles in the disordered structure of bionanocomposites [33], [34], [48]-[50]. 
A.M. Salaberría1, R. Teruel-Juanes2, JD.Badia2,3, S.C.M. Fernandes1, V. Sáenz de Juano-Arbona2, J. Labidi1, A. Ribes-Greus. Influence of chitin nanocrystals on the dielectric behaviour and conductivity of chitosan-based bionanocomposites. Composites Science and Technology 2018; $167: 323-330$
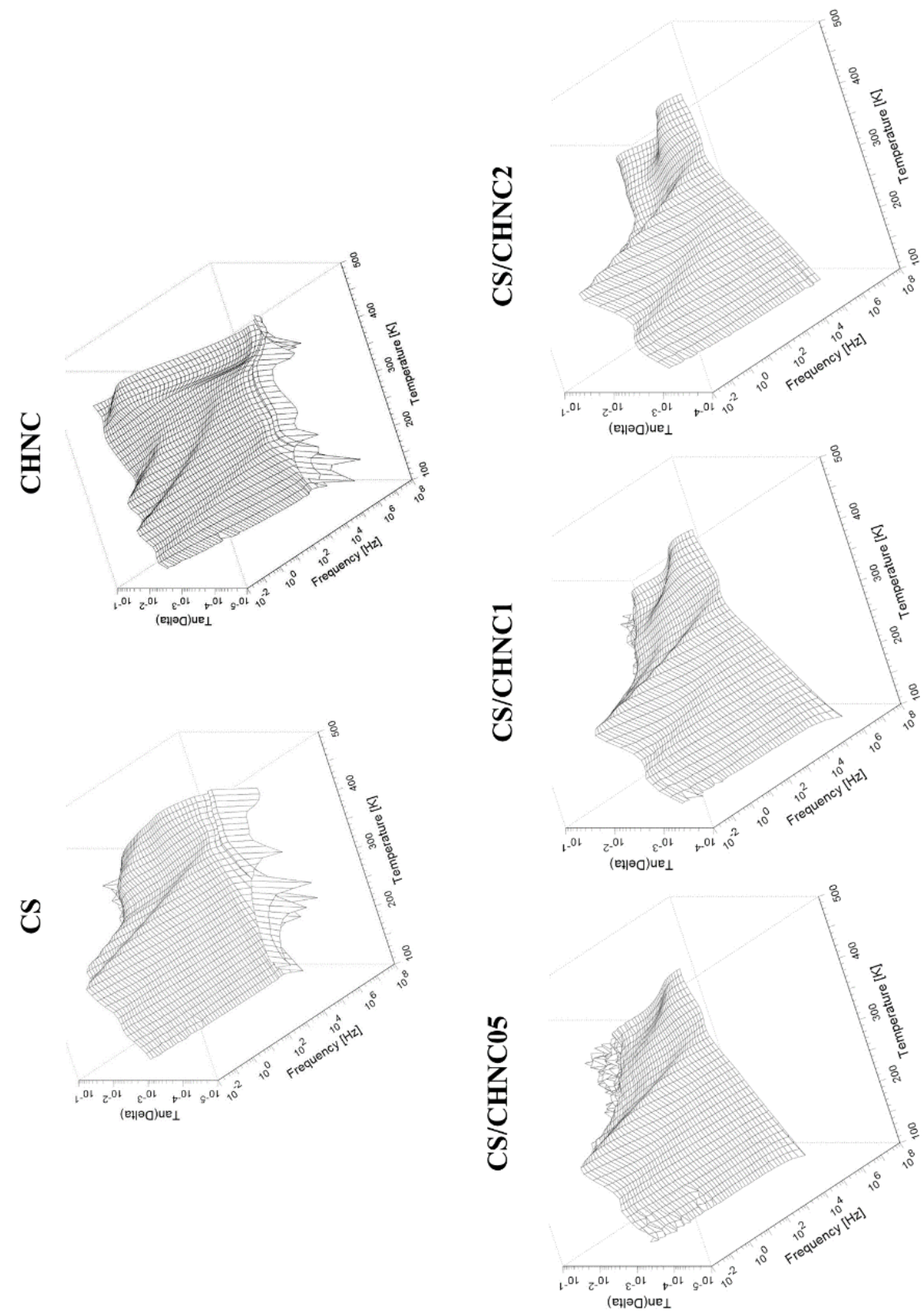

Figure 1. 3D plot of the imaginary component of the loss tan $\delta$ chitosan, chitin nanocrystals and their bionanocomposites 
A.M. Salaberría1, R. Teruel-Juanes2, JD.Badia2,3, S.C.M. Fernandes1, V. Sáenz de Juano-Arbona2, J. Labidi1, A. Ribes-Greus. Influence of chitin nanocrystals on the dielectric behaviour and conductivity of chitosan-based bionanocomposites. Composites Science and Technology 2018; 167:323-330
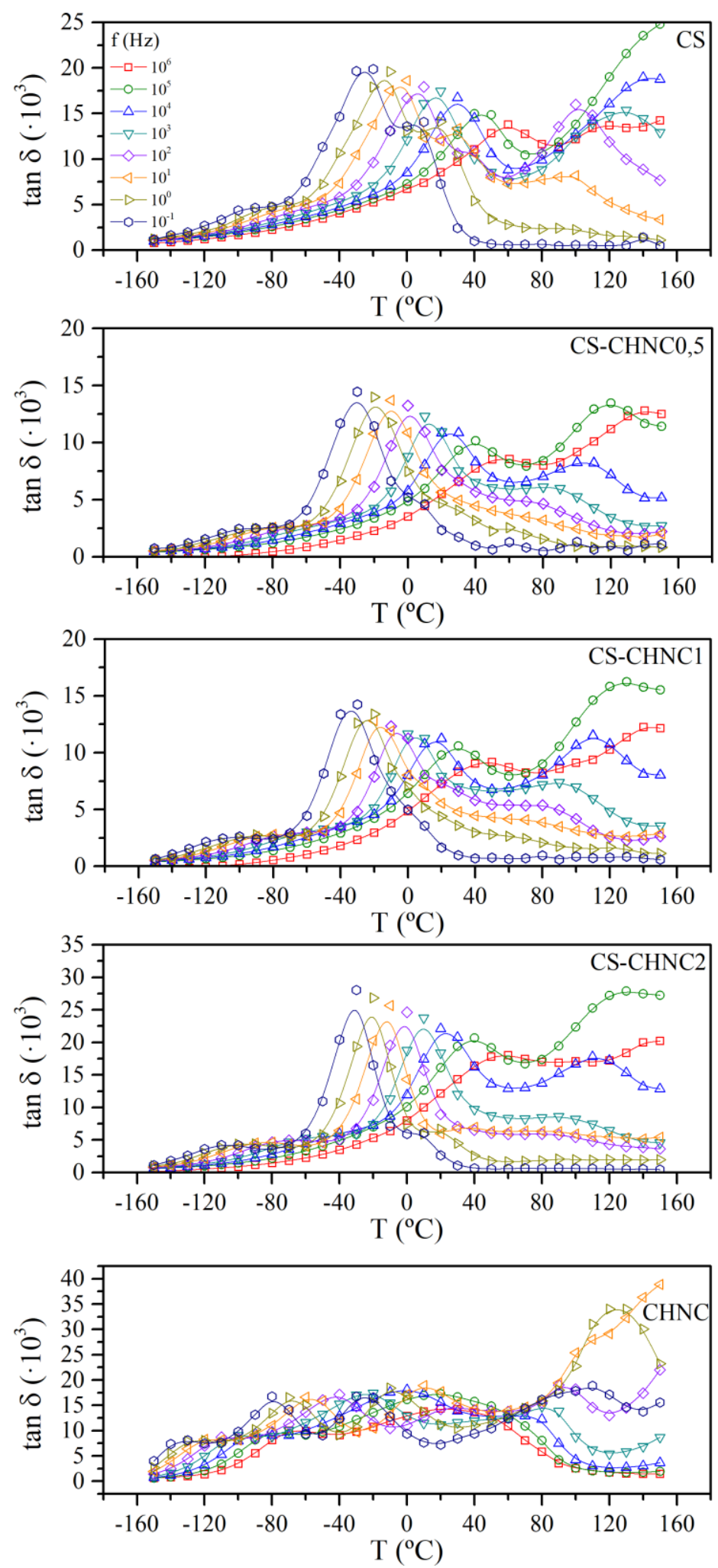

Figure 2. Isochrones of $\tan \delta$ of chitosan, chitin nanocrystals and their bionanocomposites 
A.M. Salaberría1, R. Teruel-Juanes2, JD.Badia2,3, S.C.M. Fernandes1, V. Sáenz de Juano-Arbona2, J. Labidi1, A. Ribes-Greus. Influence of chitin nanocrystals on the dielectric behaviour and conductivity of chitosan-based bionanocomposites. Composites Science and Technology 2018; 167:323-330

In order to assess the influence of chitin nanocrystals CHNC on the chitosan/chitin CS/CHNC bionanocomposites, the dielectric curves were deconvoluted by means of the Charlesworth method [51] using Havriliak-Negami HN fitting functions (Eq. 2) [52], [53].

$$
\varepsilon^{*}(w)-\varepsilon_{\infty}=\sum_{k} \operatorname{Im}\left[\frac{\Delta \varepsilon}{\left\{1+\left(i w \tau_{H N k}\right)^{A_{k}}\right\}^{B_{k}}}\right] \quad(E q .2)
$$

where $A_{k}$ and $B_{k}$ are parameters corresponding to the width and asymmetry of the relaxation respectively, which deviation from unity reveal the non-Debye relaxation behaviour; $\tau_{H N}$ is the Havriliak-Negami relaxation time, and $k$ represents the number of the individual HN contributions, as explained elsewhere [54].

Table 1 shows a summary of the $A_{k}$ and $B_{k}$ parameters of the Havriliak-Negami function of chitosan, chitin nanocrystals and the chitosan/chitin bionanocomposites at four temperatures (183, 303, 323 and $393 \mathrm{~K})$. These temperatures were chosen so that the values for each relaxation and each material could appear.

Table 1. $A k$ and $B k$ parameters for the Havriliak-Negami function for chitosan, chitin nanocrystals and chitin/chitosan bionanocomposites.

\begin{tabular}{|c|c|c|c|c|c|c|}
\hline \multirow{2}{*}{$\begin{array}{c}\text { H. N. } \\
\text { Parameters }\end{array}$} & $\mathbf{T}(\mathbf{K})$ & 183 & 183 & 303 & 393 & 323 \\
\hline & Relaxation & $\gamma$ & $\boldsymbol{\beta}$ & $\alpha$ & $\rho_{I}$ & $\rho_{\text {II }}$ \\
\hline \multirow{5}{*}{$A k$} & $\mathrm{CS}$ & - & 0.45 & 0.56 & 0.66 & 0.92 \\
\hline & CS-CHNC05 & 0.61 & 0.21 & 0.41 & 0.60 & 1.00 \\
\hline & CS-CHNC1 & 0.76 & 0.24 & 0.48 & 0.54 & 0.78 \\
\hline & CS-CHNC2 & 0.67 & 0.28 & 0.61 & 0.58 & 1.00 \\
\hline & CHNC & - & 0.43 & - & - & 0.34 \\
\hline \multirow{5}{*}{$B \boldsymbol{k}$} & $\mathrm{CS}$ & - & 0.83 & 0.82 & 0.41 & 0.26 \\
\hline & CS-CHNC05 & 0.35 & 0.89 & 1.00 & 1.00 & 0.69 \\
\hline & CS-CHNC1 & 1.00 & 0.81 & 1.00 & 1.00 & 0.40 \\
\hline & CS-CHNC2 & 1.00 & 0.89 & 0.33 & 0.96 & 0.53 \\
\hline & CHNC & - & 1.00 & - & - & 0.88 \\
\hline
\end{tabular}


A.M. Salaberría1, R. Teruel-Juanes2, JD.Badia2,3, S.C.M. Fernandes1, V. Sáenz de Juano-Arbona2, J. Labidi1, A. Ribes-Greus. Influence of chitin nanocrystals on the dielectric behaviour and conductivity of chitosan-based bionanocomposites. Composites Science and Technology 2018; 167:323-330

An inspection of the parameters $A_{k}$ and $B_{k}$ corresponding to each one of the relaxation for all materials indicated that the $B_{k}$ was very close to the unit and slightly dependent of temperature. This fact denotes the absence of skewness in the high frequency and a symmetric behavior. The values of $A_{k}$ were lower than those of $B_{k}$ and increased with the temperature, which suggests that the $\alpha, \rho_{\mathrm{I}}$ and $\rho_{\mathrm{II}}$ relaxations exhibited a rather narrow distribution of relaxation times than that of the $\gamma$ and $\beta$ relaxations.

\subsection{Identification of cooperative behaviour of dielectric relaxations}

In order to discriminate cooperative from non-cooperative segmental movements, the temperature dependence of the relaxation times with the temperature was analysed by means of the Eyring model [55], [56]. Non-cooperative relaxations, due to the independent motion of kinetic units, follow a zero entropy law, and the relaxations lie within the line represented by Equation 3 [57]

$$
E a=R T^{\prime}\left[1+\ln (k / 2 p h)+\ln T^{\prime}\right]=R T^{\prime}\left[22.92+\ln T^{\prime}\right] \quad(E q .3)
$$

where $T^{\prime}$ is the temperature at which the frequency of the corresponding relaxation is $f=1 \mathrm{~Hz}$.

The Arrhenius map and Eyring plot of the macromolecular segmental relaxations of chitosan/chitin $\mathrm{CS} / \mathrm{CHNC}$ bionanocomposites are shown in 
A.M. Salaberría1, R. Teruel-Juanes2, JD.Badia2,3, S.C.M. Fernandes1, V. Sáenz de Juano-Arbona2, J. Labidi1, A. Ribes-Greus. Influence of chitin nanocrystals on the dielectric behaviour and conductivity of chitosan-based bionanocomposites. Composites Science and Technology 2018; 167:323-330

Figure 3. On the one hand, linear evolutions of $\log f$ vs $T^{-1}$ indicate non-cooperative intramolecular segmental motions, generally ascribed to movements of side or radical groups, and therefore lie close to the zero-entropy line in the Eyring plot. On the other hand, non-linear evolutions, identifiable at higher temperatures, i.e. lower $\mathrm{T}^{-1}$, are representative of cooperative intermolecular movements related to high-order segmental motions in the backbone. A specific assignation of movements is discussed in the following sections. From lower to higher temperatures, the relaxations have been labelled as $\gamma$ and $\beta$ for non-cooperative movements and $\alpha, \rho_{\text {I }}$ and $\rho_{\text {II }}$ for cooperative movements. The $\rho_{\text {I }}$ and $\rho_{\text {II }}$ relaxations occur at the rubbery state and usually appear overlapped by the conductivity of dipoles at DETA analyses.
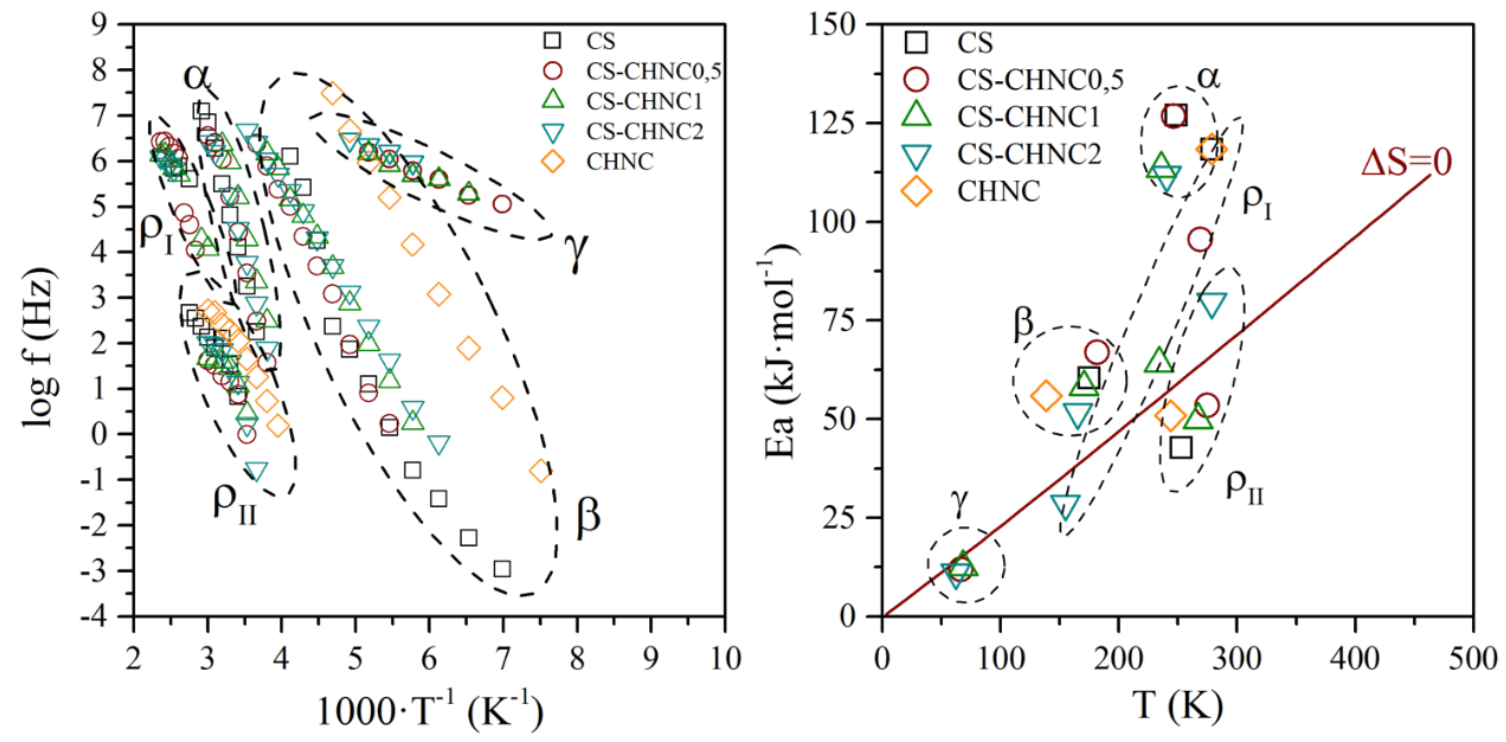

Figure 3. Arrhenius maps of the relaxations of chitosan, chitin nanocrystals and chitin/chitosan bionanocomposites (left) ; Eyring plot (right)

\subsection{Analysis of non-cooperative intramolecular relaxations in the glassy state}


A.M. Salaberría1, R. Teruel-Juanes2, JD.Badia2,3, S.C.M. Fernandes1, V. Sáenz de Juano-Arbona2, J. Labidi1, A. Ribes-Greus. Influence of chitin nanocrystals on the dielectric behaviour and conductivity of chitosan-based bionanocomposites. Composites Science and Technology 2018; 167:323-330

The dielectric processes appearing in the glassy state were labelled $\gamma$ and $\beta$ in increasing order of temperatures. At low temperatures, below the glass-rubber relaxation, the molecular mobility is severely restrictive, being the movements generally ascribed to localised movements of secondary groups. Both intramolecular non-cooperative molecular relaxations were described in terms of the Arrhenius equation (Eq. 4)

$$
f_{\max }=f_{0} \exp \left(\frac{-E a}{R \cdot T}\right)
$$

where $f$ and $\mathrm{T}$ are the linear frequency and temperature of the DETA tests, $E a$ is the apparent activation energy, $f_{0}$ is a pre-exponential term, and $\mathrm{R}$ is the ideal gas constant $\left(8.31 \mathrm{~J} \cdot \mathrm{mol}^{-1} \cdot \mathrm{K}^{-}\right.$ $\left.{ }^{1}\right)$. Table 2 gathers the results of Arrhenius fitting to $\gamma$ and $\beta$ intramolecular non-cooperative relaxations.

As the interaction of water with the components of bionanocomposites and the crystallinity have been found relevant [35], [36], [58] to understand the $\beta$-relaxation, the corresponding values of these parameters for chitin, chitosan and nanobiocomposites were calculated and taken into account in the discussion of results. The crystallinity of the biocomposites have been analysed by means of the X-ray diffraction patterns, following the experimental methodology described in section 2.4. Likewise, the humidity percentage were assessed by thermogravimetric analysis as described in the section 2.3. The slight mass-loss observed before the onset temperature at around $373 \mathrm{~K}\left(100{ }^{\circ} \mathrm{C}\right)$ has been considered as the proportion of vaporized water. Table 3 shows the humidity percentage and the crystallinity index values for chitin, chitosan, and chitin/chitosan bionanocomposites. It was shown that the humidity percentage of each film decreased with the increment of CHNC on the bionanocomposite. As expected, the chitosan film presents the lowest crystallinity with $16 \%$. On the other hand, chitin $-15-$ 
A.M. Salaberría1, R. Teruel-Juanes2, JD.Badia2,3, S.C.M. Fernandes1, V. Sáenz de Juano-Arbona2, J. Labidi1, A. Ribes-Greus. Influence of chitin nanocrystals on the dielectric behaviour and conductivity of chitosan-based bionanocomposites. Composites Science and Technology 2018; 167:323-330

nanocrystals exhibit $87 \%$, and influence strongly in the final crystallinity of the nanocomposites. 
A.M. Salaberría1, R. Teruel-Juanes2, JD.Badia2,3, S.C.M. Fernandes1, V. Sáenz de Juano-Arbona2, J. Labidi1, A. Ribes-Greus. Influence of chitin nanocrystals on the dielectric behaviour and conductivity of chitosanbased bionanocomposites. Composites Science and Technology 2018; 167:323-330

1 Table 2. Results from dielectric analysis to chitosan, chitin nanocrystals and chitin/chitosan bionanocomposites. Arrhenius fits to intra-molecular relaxations, VFTH

fits to inter-molecular relaxations and Evolution of dynamic fragility parameters

\begin{tabular}{|c|c|c|c|c|c|c|c|c|}
\hline \multirow[b]{2}{*}{ Material } & \multicolumn{4}{|c|}{ Intra-molecular relaxations / Arrhenius fits } & \multicolumn{4}{|c|}{ Inter-molecular relaxations / VFTH fits } \\
\hline & Tmax-1kHz (K) & $\mathbf{E a}\left(\mathbf{k J} \cdot \mathbf{m o l}^{-1}\right)$ & $\operatorname{logf0}(\mathrm{Hz})$ & $\mathbf{R}^{2}$ & $\log \mathrm{f}_{0}(\mathrm{~Hz})$ & $\mathbf{T}_{\mathrm{VFTH}}(\mathbf{K})$ & D & $\mathbf{R}^{2}$ \\
\hline & \multicolumn{4}{|c|}{$\gamma$-relaxation } & \multicolumn{4}{|c|}{$\alpha$-relaxation } \\
\hline$\overline{C S}$ & - & - & - & - & $12.4 \pm 0.2$ & $197.1 \pm 0.4$ & $9.1 \pm 0.4$ & 0.991 \\
\hline $\mathrm{CS} / \mathrm{CHNC} 0.5$ & $99.4 \pm 0.5$ & $12.5 \pm 0.6$ & $9.6 \pm 0.2$ & 0.990 & $12.1 \pm 0.3$ & $192.6 \pm 0.6$ & $9.0 \pm 0.4$ & 0.989 \\
\hline$\overline{\mathrm{CS} / \mathrm{CHNC} 1}$ & $97.8 \pm 0.5$ & $11.9 \pm 0.1$ & $9.4 \pm 0.3$ & 0.965 & $12.3 \pm 0.4$ & $189.6 \pm 0.4$ & $8.9 \pm 0.4$ & 0.988 \\
\hline \multirow[t]{2}{*}{ CS/CHNC2 } & $91.4 \pm 0.5$ & $11.1 \pm 0.9$ & $9.3 \pm 0.3$ & 0.981 & $11.4 \pm 0.1$ & $188.8 \pm 0.2$ & $8.7 \pm 0.2$ & 0.997 \\
\hline & \multicolumn{4}{|c|}{$\beta$-relaxation } & \multicolumn{4}{|c|}{$\rho_{\mathrm{I}}-$ relaxation } \\
\hline CS & $209.6 \pm 0.5$ & $60.3 \pm 4.8$ & $18.0 \pm 1.2$ & 0.934 & $14.8 \pm 0.7$ & $133.8 \pm 0.4$ & $38.2 \pm 2.7$ & 0.978 \\
\hline CS/CHNC0.5 & $214.9 \pm 0.5$ & $66.9 \pm 1.3$ & $19.3 \pm 0.41$ & 0.995 & $15.2 \pm 1.3$ & $126.1 \pm 0.5$ & $45.5 \pm 6.3$ & 0.877 \\
\hline $\mathrm{CS} / \mathrm{CHNC1}$ & $205.2 \pm 0.5$ & $58.1 \pm 1.1$ & $17.8 \pm 0.2$ & 0.998 & $11.7 \pm 0.4$ & $119.5 \pm 0.5$ & $31.1 \pm 2.2$ & 0.975 \\
\hline CS/CHNC2 & $202.3 \pm 0.5$ & $51.7 \pm 0.5$ & $16.3 \pm 0.2$ & 0.998 & $8.6 \pm 0.3$ & $114.0 \pm 0.2$ & $15.6 \pm 2.0$ & 0.947 \\
\hline CHNC & $161.4 \pm 0.5$ & $55.9 \pm 0.5$ & $21.1 \pm 0.2$ & 0.998 & - & - & - & - \\
\hline \multicolumn{9}{|c|}{ Dynamic fragility parameters of $\alpha$-relaxation } \\
\hline Material & \multicolumn{2}{|c|}{$\mathbf{B}(\mathbf{K})$} & $\mathbf{m}$ & \multicolumn{2}{|c|}{$\Phi(\%)$} & $\alpha_{\mathrm{T}}\left(\cdot 10^{4} \mathrm{~K}^{-1}\right)$ & \multicolumn{2}{|c|}{$\mathbf{E a}_{\mathrm{TG}}\left(\mathrm{kJ} \cdot \mathrm{mol}^{-1}\right)$} \\
\hline $\mathrm{CS}$ & \multicolumn{2}{|c|}{$1793 \pm 68$} & $77 \pm 3$ & \multicolumn{2}{|c|}{$2.8 \pm 0.1$} & $5.5 \pm 0.2$ & \multicolumn{2}{|c|}{$367.1 \pm 13.9$} \\
\hline CS/CHNC0.5 & \multicolumn{2}{|c|}{$1742 \pm 73$} & $73 \pm 3$ & \multicolumn{2}{|c|}{$2.8 \pm 0.1$} & $5.7 \pm 0.2$ & \multicolumn{2}{|c|}{$342.0 \pm 14.3$} \\
\hline $\mathrm{CS} / \mathrm{CHNC} 1$ & \multicolumn{2}{|c|}{$1688 \pm 84$} & $70 \pm 3$ & \multicolumn{2}{|c|}{$2.9 \pm 0.1$} & $5.9 \pm 0.3$ & \multicolumn{2}{|c|}{$322.2 \pm 16.1$} \\
\hline CS/CHNC2 & \multicolumn{2}{|c|}{$1653 \pm 38$} & $69 \pm 2$ & \multicolumn{2}{|c|}{$3.0 \pm 0.1$} & $6.1 \pm 0.1$ & \multicolumn{2}{|c|}{$313.3 \pm 7.2$} \\
\hline
\end{tabular}

4

- 17 - 
A.M. Salaberría1, R. Teruel-Juanes2, JD.Badia2,3, S.C.M. Fernandes1, V. Sáenz de Juano-Arbona2, J. Labidi1, A. Ribes-Greus. Influence of chitin nanocrystals on the dielectric behaviour and conductivity of chitosan-based bionanocomposites. Composites Science and Technology 2018; 167:323-330

Table 3. Humidity content and crystallinity index of chitosan-chitin chitin, chitosan, and chitin/chitosan

bionanocomposites

\begin{tabular}{lcc}
\hline \multicolumn{1}{c}{ Material } & Humidity (\%) & C.I (\%) \\
\hline $\mathrm{CS}$ & 12.8 & 16.2 \\
\hline $\mathrm{CS} / \mathrm{CHNC0.5}$ & 8.6 & 87.5 \\
\hline $\mathrm{CS} / \mathrm{CHNC} 1$ & 7.1 & 92.8 \\
\hline $\mathrm{CS} / \mathrm{CHNC2}$ & 5.4 & 91.8 \\
\hline $\mathrm{CHNC}$ & 2.9 & 87.1 \\
\hline
\end{tabular}

The $\gamma$-relaxation, at temperatures of 91 to $99 \mathrm{~K}\left(-182\right.$ to $\left.-175^{\circ} \mathrm{C}\right)$, was only observed for the bionanocomposites and not for pure chitosan or chitin. The apparent activation energy was $\sim 11.5 \mathrm{~kJ} \cdot \mathrm{mol}^{-1}$ for all bionanocomposites, without relevant effect of nor the amount of chitin CHNC neitherthe moisture content of the bionanocomposites. The molecular origin of this weak relaxation might be due to local movements of the carbonyl group present in CHNC triggered by the environment of the CS matrix.

The $\beta$-relaxation still appeared in the low temperature range, 202 to $215 \mathrm{~K}$ ( -71 to $\left.-58{ }^{\circ} \mathrm{C}\right)$, according to literature [33], [59]-[61]. It showed activation energies around 50-65 $\mathrm{kJ} \cdot \mathrm{mol}^{-1}$. This process is usually observed in polysaccharide-based materials but different molecular origins for this relaxation have been suggested in the literature, which were discussed by Einfeldt et al [49]. These relaxations process are mainly attributed to local main chain motions, related to fluctuations within the glycosidic bonds. In wet samples, this relaxation could also be assigned to orientation motions of a mixed phase of both polysaccharide and water, which is formed in wet systems by a swelling process. These materials have a strong affinity for water and may be readily hydrated forming macromolecules with rather disordered structures [34]. These authors reported apparent activation energies around $\sim 47 \mathrm{~kJ} \cdot \mathrm{mol}^{-1}$ for dry chitosan. However, A. Nogales et al. reported a value for the apparent activation energy of $\sim 71 \mathrm{~kJ} \cdot \mathrm{mol}^{-}$ $-18-$ 
A.M. Salaberría1, R. Teruel-Juanes2, JD.Badia2,3, S.C.M. Fernandes1, V. Sáenz de Juano-Arbona2, J. Labidi1, A. Ribes-Greus. Influence of chitin nanocrystals on the dielectric behaviour and conductivity of chitosan-based bionanocomposites. Composites Science and Technology 2018; 167:323-330

${ }^{1}$ [62]. The values obtained in the present work agree with these references because they are between both results. Table 2 shows that the values of the Ea display a certain tendency to decrease when the percentage of humidity in the bionanocomposites decrease, due to the increase of chitin nanocrystals.

The bionanocomposite CS-CHNC0.5 showed a maximum value of $E a$. The presence of water may give rise to the formation of hydrogen bonds with the $-\mathrm{OH}$ and $-\mathrm{NH}_{2}$ groups. It is consistent with a local relaxation in which both the polysaccharide and the water are involved. Thus, the apparent activation energy of this process increased due to these interactions between the -OH and $-\mathrm{NH}_{2}$ groups which consequently increased with the water content. However, there was no direct relationship between the increase in crystallinity and the increase in activation energy. This result seems to indicate that it fundamentally was the percentage of humidity, as a consequence of molecular interactions, the factor that most influences the $\beta$-relaxation process

\subsection{Analysis of cooperative intermolecular relaxations in the vicinities of the glass transition and in the rubbery state}

At high temperatures, a very high intensity relaxation zone constituted by at least three relaxations were observed, labelled as $\alpha$ and $\rho_{I}-\rho_{I I}$ in increasing temperatures, for the glassrubber (GR) relaxation and over-GR relaxations, respectively. At temperatures higher than the glass-rubber relaxation, the dependence of the relaxation times with the temperature for segmental movements are usually governed by a Vogel-Fulcher-Tammann-Hesse model [63], [64] (VTFH, Eq. 5) 
A.M. Salaberría1, R. Teruel-Juanes2, JD.Badia2,3, S.C.M. Fernandes1, V. Sáenz de Juano-Arbona2, J. Labidi1, A. Ribes-Greus. Influence of chitin nanocrystals on the dielectric behaviour and conductivity of chitosan-based bionanocomposites. Composites Science and Technology 2018; 167:323-330

$$
f_{\max }={ }_{0} \cdot \exp \left(-\frac{B}{T-T_{V F T H}}\right)=f_{0} \cdot \exp \left(-\frac{D \cdot T_{V F T H}}{T-T_{V F T H}}\right)
$$

,where $B(K)$ is an activation parameter, $f_{0}$ is a pre-exponential term, and $T_{V F T H}(\mathrm{~K})$ the VFTH temperature. $B$ can be rewritten in terms of the fragility parameter $D$ and $T_{V F T H}$, according to $B=D \cdot T_{V F T H} . D$ is a non-dimensional parameter that varies from $\leq 6$ to $\geq 15$ from fragile to strong glass-formers. The so-called fragility index $m$, was obtained by $E q .6$, and represents the deviation from the Arrhenius behaviour, between 16 and $\geq 200$ for strong to fragile glassformers [65] [66].

$$
m=\left.\frac{\partial \log (\tau)}{\partial\left(\frac{T_{G}}{T}\right)}\right|_{T g}=\frac{B \cdot T_{g}}{\ln (10) \cdot\left(T_{g}-T_{V F T H}\right)^{2}}
$$

The free volume coefficient $\Phi$ [67], [68], the thermal expansion coefficient $\alpha_{\mathrm{T}}$ [69] and the apparent activation energy related to the glass transition temperature $\mathrm{Ea}_{\mathrm{Tg}}$ were respectively calculated according to $E q 7,8$, and 9 .

$$
\begin{aligned}
\left.\phi\right|_{T g} & =\frac{\left(T_{g}-T_{V F T H}\right)}{B} \\
\left.\alpha_{T}\right|_{T g} & =\frac{1}{B} \\
E a_{T g} & =R \cdot \frac{\partial \ln \tau}{\partial(1 / T)}=\frac{R \cdot B}{\left(1-\frac{T_{V F T H}}{T_{g}}\right)^{2}}
\end{aligned}
$$


A.M. Salaberría1, R. Teruel-Juanes2, JD.Badia2,3, S.C.M. Fernandes1, V. Sáenz de Juano-Arbona2, J. Labidi1, A. Ribes-Greus. Influence of chitin nanocrystals on the dielectric behaviour and conductivity of chitosan-based bionanocomposites. Composites Science and Technology 2018; 167:323-330

The $\alpha$-relaxation is related to the cooperative intermolecular movements of the glass-rubber relaxation. The segmental mode produce pronounced changes are observed in the mechanical, thermal and dielectric properties. The mean relaxation time associated to the cooperative motions of polymer segments of the main backbone also change many orders of magnitude.

Montiel-González et al. registered the dilatometric activity and suggested that a volumetric transition temperature could be assigned at ca. $324 \mathrm{~K}$ for chitin and $332 \mathrm{~K}$ for chitosan [61]. The $\alpha$-relaxation appeared for chitosan CS and chitosan/chitin bionanocomposites CS/CHNC, but not for chitin. The glass transition of chitosan was also been determined by DSC following the methodology described in section 2.3. The calorimetric thermograms of chitosan are shown in the Figure 4. The first heating shows an endothermic peak at about $100{ }^{\circ} \mathrm{C}$ which is attributed to the moisture of sample. This result are in agreement with the ones obtained by the thermogravimetric analyses. To eliminate the effect of moisture, a second heating run was performed. In the second heating, a slight change of inclination can be noted at $164.7^{\circ} \mathrm{C}$, corresponding with the Tg of chitosan film and attributed to the movements of the of the chains that constitute the amorphous fraction of chitosan, in agreement with literature [70].

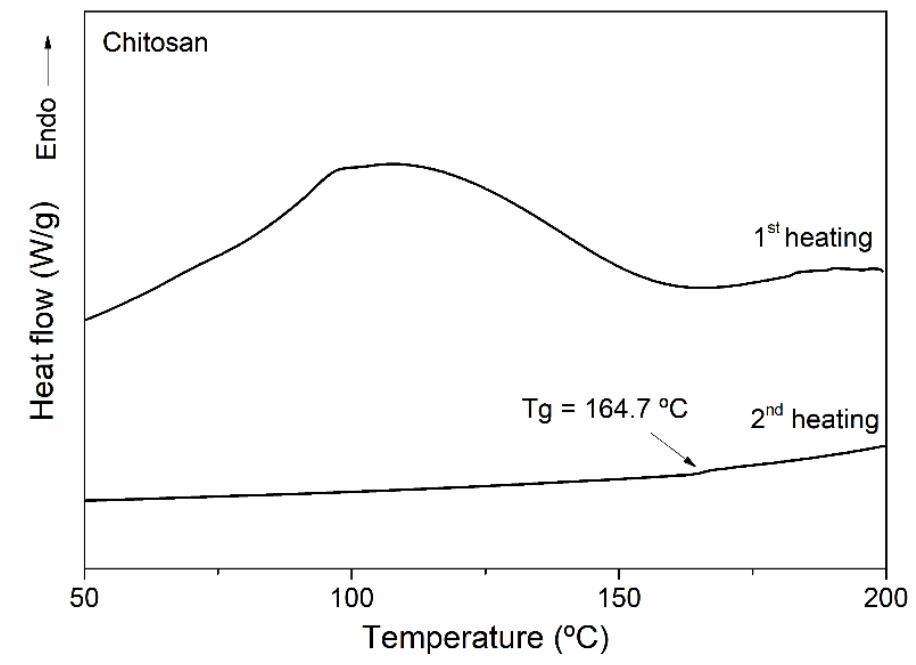

Figure 4. DSC calorimetric thermograms of chitosan 
A.M. Salaberría1, R. Teruel-Juanes2, JD.Badia2,3, S.C.M. Fernandes1, V. Sáenz de Juano-Arbona2, J. Labidi1, A. Ribes-Greus. Influence of chitin nanocrystals on the dielectric behaviour and conductivity of chitosan-based bionanocomposites. Composites Science and Technology $2018 ; 167: 323-330$

Table 2 shows the results of the VFTH fitting to the $\alpha$-relaxation, taking as reference the temperature corresponding to the maximum of the $\tan (\delta)$ at the lowest frequency $\left(10^{-1} \mathrm{~Hz}\right)$. Table 2 also gathers the results of dynamic fragility, free-volume coefficient, thermal expansion coefficient and apparent activation energy. A decrease in the fragility parameters $(D$, $B$ ) was registered the higher the amount of chitin nanocrystals was. Accordingly, the dynamic fragility $m$ and the apparent activation energy $E a_{T g}$ decreased when the chitin content increase. These results can be explained in terms of the free volume at the vicinities of the glass transition, which increased with higher amount of chitin nanocrystals CHNC. This fact was not related with a plastifying effect of water because the apparent activation energy decreased when the water content decreased and the chitin content increased, contrarily to what it could be expected. Actually, this result confirms that the spatial configuration of these polymer segments can be variable with the humidity content. Somewhat, it is possible to ascribe it to the formation of macromolecular aggregates or clusters, due to the interactions between the $-\mathrm{OH}$ and $-\mathrm{NH}_{2}$ groups. It might increase the free volume within the chitosan matrix, but hindering the cooperative movement of molecular chains. Summing up, the apparent activation energy increased because the water promoted macromolecular clusters.

The $\rho_{I}$ and $\rho_{I I}$ relaxations appeared immediately after the $\alpha$-relaxation, one at high frequencies, $\rho_{I}$ between $10^{3}$ and $10^{7} \mathrm{~Hz}$, and another at low frequencies, $\rho_{I I}$ between $10^{-1}$ and $10^{3} \mathrm{~Hz}$, as shown in

Figure. In polysaccharides and biopolymers, similar relaxations can be found at low frequencies and high temperatures [33], [60], [71]. Despite the relaxations above the glassrubber relaxation are rarely reported, since most of them are usually masked by an overlapping $-22-$ 
A.M. Salaberría1, R. Teruel-Juanes2, JD.Badia2,3, S.C.M. Fernandes1, V. Sáenz de Juano-Arbona2, J. Labidi1, A. Ribes-Greus. Influence of chitin nanocrystals on the dielectric behaviour and conductivity of chitosan-based bionanocomposites. Composites Science and Technology 2018; 167:323-330

relaxation related to the conductivity effect of dipoles, the relaxations have been fitted to the VFTH equation. $\rho_{I I}$ did not give reliable parameters with high error values. $\rho_{I}$ results are shown in Table 2. Although the error values are significant, a sort of tendency to diminish the value of $D$ in the bionanocomposites with higher amounts of CHNC nanocrystals was found.

\subsection{Effect of chitin nanocrystals on the electric conductivity}

The complex conductivity was also analyzed following the experimental procedure descripted in the section 2.1 at a frequency range of $\mathrm{f}=10^{-2}-10^{7} \mathrm{~Hz}$ under isothermal conditions at temperature of 298K. As shown in Figure 5, the contribution of direct current (DC) is important at low frequencies, while the contribution of the alternant current (AC) was dependent on frequency, which was important at high frequencies. The dependence of the AC conductivity with the frequency, has been represented by $A f S$, where A is a scalar and $\mathrm{S}$ is the frequency power, which is generally lower than or equal to one. The total electrical conductivity was evaluated as the addition of the $\sigma_{\mathrm{DC}}$ and $\sigma_{\mathrm{AC}}$ [72], [73] Thus, the total electric conductivity can be calculated by the following power expression:

$$
\sigma_{\text {tot }}(f)=\sigma_{D C}+A f^{S} \quad(E q .10)
$$

On the one hand, the values of $\sigma_{\mathrm{DC}}$ were calculated by extrapolating the $\sigma$ plateau to $(\mathrm{f} \rightarrow 0$ ) [74]. It is clearly observed that the conductivity depends on the composition. On the other hand, the parameters which represent the dependence of the AC conductivity with the frequency, has been calculated from the slope and the ordinate at the origin. Table 4 displays the obtained results for the power fitting, with $\mathrm{R}^{2}$ correlation values of 0.9999 in all cases. The frequency exponent $\mathrm{S}$ of the AC conductivity slightly increased for the bionanocomposites when the chitin 
A.M. Salaberría1, R. Teruel-Juanes2, JD.Badia2,3, S.C.M. Fernandes1, V. Sáenz de Juano-Arbona2, J. Labidi1, A. Ribes-Greus. Influence of chitin nanocrystals on the dielectric behaviour and conductivity of chitosan-based bionanocomposites. Composites Science and Technology 2018; 167:323-330

content increased until the CS/CHNC had the same percentage of chitosan and chitin. However, it should be noted that these differences are very small.

Table 4. Dependence of the AC conductivity with the frequency of chitosan, chitin nanocrystals and chitin/chitosan bionanocomposites

\begin{tabular}{lcc}
\multicolumn{1}{c}{ Material } & $\mathbf{A} * \mathbf{1 0}{ }^{\mathbf{1 2}}$ & $\mathbf{S}$ \\
\hline $\mathrm{CS}$ & $7,82 \pm 0,06$ & $0,90 \pm 0,0005$ \\
\hline $\mathrm{CS} / \mathrm{CHCN} 05$ & $1,86 \pm 0,05$ & $0,92 \pm 0,0016$ \\
\hline $\mathrm{CS} / \mathrm{CHCN} 1$ & $1,44 \pm 0,03$ & $0,94 \pm 0,0015$ \\
\hline $\mathrm{CS} / \mathrm{CHCN} 2$ & $3,00 \pm 0,14$ & $0,90 \pm 0,0030$ \\
\hline $\mathrm{CHCN}$ & $3,85 \pm 0,05$ & $0,91 \pm 0,0008$
\end{tabular}
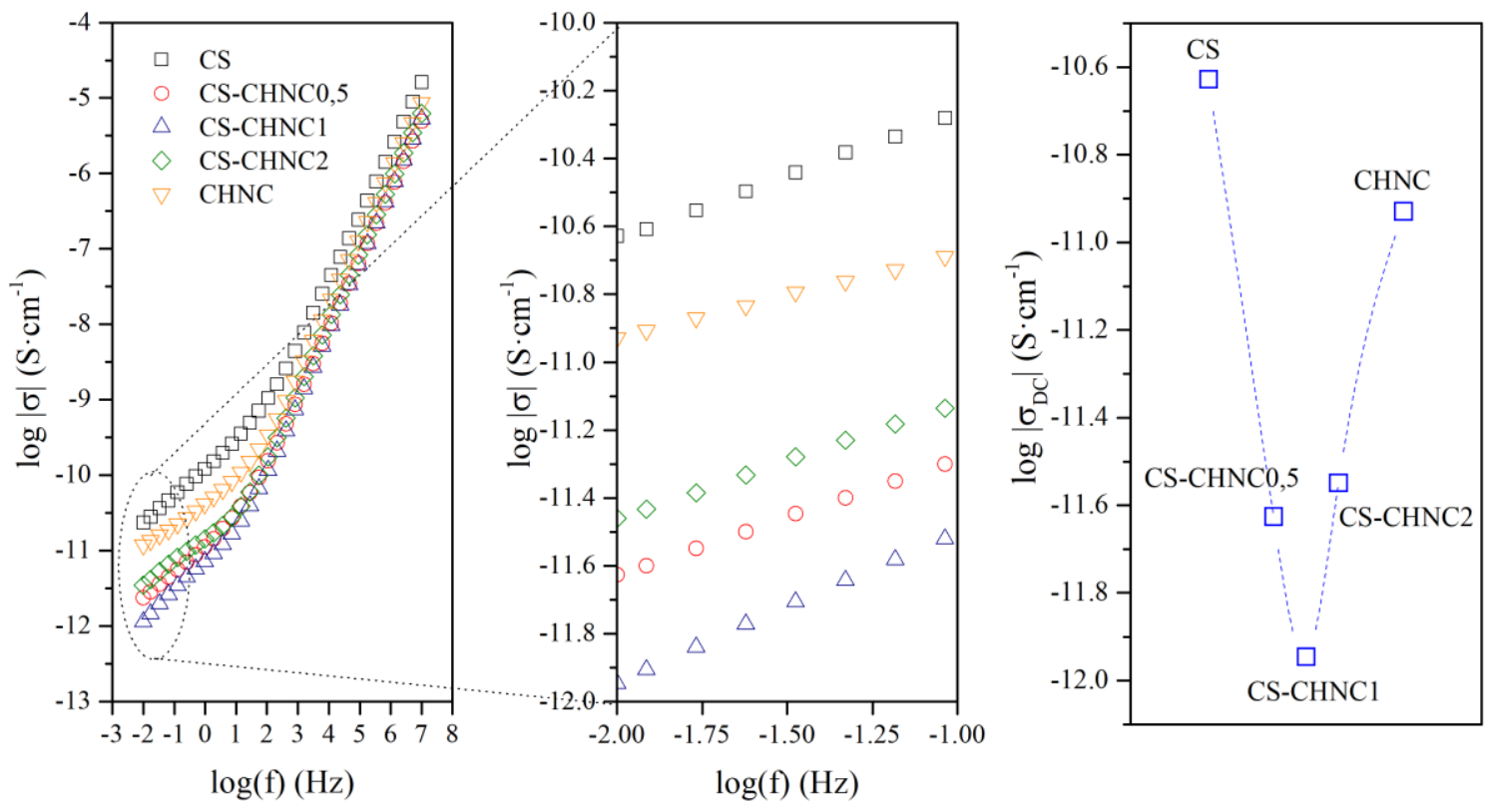

Figure 5. Conductivity of chitosan-chitin nanocrystals bionanocomposites

As can be observed in Figure 5, the DC conductivity decreased for the bionanocomposites when the chitin content increased until the $\mathrm{CS} / \mathrm{CHNC}$ had the same percentage of chitosan and 
A.M. Salaberría1, R. Teruel-Juanes2, JD.Badia2,3, S.C.M. Fernandes1, V. Sáenz de Juano-Arbona2, J. Labidi1, A. Ribes-Greus. Influence of chitin nanocrystals on the dielectric behaviour and conductivity of chitosan-based bionanocomposites. Composites Science and Technology 2018; 167:323-330

chitin. Subsequently, the conductivity increased again for chitin percentages higher than $50 \%$. The dispersion of the nanocrystals of chitin within the chitosan matrix affected the overall performance of the heterogeneous system. These results are in agreement with those obtained when analysing the spectrum of dielectric relaxations. The interactions between the -OH and $\mathrm{NH}_{2}$ groups decreases the movement of the free electric charges. The chitin nanocrystals block the conductivity channels of the chitosan matrix due to lack of continuity between phases. However, if the dispersed nanocrystals are in enough quantity, but the water proportion decreased, as happened when the chitin percentages were higher than $50 \%$, the $-\mathrm{OH}$ and $-\mathrm{NH}_{2}$ interactions decreased because the $-\mathrm{OH}$ groups were in lower amount, consequently the free $\mathrm{NH}_{2}$ were more present and the conductivity increased. 
A.M. Salaberría1, R. Teruel-Juanes2, JD.Badia2,3, S.C.M. Fernandes1, V. Sáenz de Juano-Arbona2, J. Labidi1, A. Ribes-Greus. Influence of chitin nanocrystals on the dielectric behaviour and conductivity of chitosan-based bionanocomposites. Composites Science and Technology 2018; 167:323-330

\section{Conclusions}

The dielectric behaviour of bionanocomposite films based on chitosan and chitin nanocrystals can described in terms of two sub-Tg intramolecular non-cooperative $\gamma$ and $\beta$ relaxations, the intermolecular cooperative $\alpha$-relaxation and two over-Tg $\rho_{I}$ and $\rho_{I I}$ relaxations.

The $\gamma$-relaxation was ascribed to weak local movements of the carbonyl group present in CHNC, triggered by the environment of the CS matrix and therefore only observed for the bionanocomposites. The $\beta$ - and $\alpha$-relaxations were influenced by the presence of chitin nanocrystals because the addition of chitin nanocrystals decreased the tendency to absorb water and increase the free volume. The interactions between the $-\mathrm{OH}$ and $-\mathrm{NH}_{2}$ groups hinders the cooperative movement of molecular chains and increases the apparent activation energy.

The increase of free volume, understood as a lack of continuity between phases and the different proportions of $-\mathrm{OH}$ and $-\mathrm{NH}_{2}$ groups, gave rise to a decrease of conductivity of the bionanocomposites, with respect to neat chitosan and chitin nanocrystals, offering a minimum for the bionanocomposite with a $50 \%$ of chitin content.

\section{Acknowledgments}

The European Regional Development Funds and the Spanish Ministry of Science and Innovation for the concession of Research Projects ENE2014-53734-C2-1-R, UPOV13-3E1947 and ENE2017-86711-C3-1-R are appreciated. Generalitat Valenciana is acknowledged for the project APOSTD14/041 for JD Badia. The authors are thankful for the financial support from the Department of Education of the Basque Government (IT1008-18). 
A.M. Salaberría1, R. Teruel-Juanes2, JD.Badia2,3, S.C.M. Fernandes1, V. Sáenz de Juano-Arbona2, J. Labidi1, A. Ribes-Greus. Influence of chitin nanocrystals on the dielectric behaviour and conductivity of chitosan-based bionanocomposites. Composites Science and Technology 2018; 167:323-330

\section{References}

[1] J. D. Badia, O. Gil-Castell, and A. Ribes-Greus, "Long-term properties and end-of-life of polymers from renewable resources," Polym. Degrad. Stab., Mar. 2017.

[2] D. Raabe, C. Sachs, and P. Romano, "The crustacean exoskeleton as an example of a structurally and mechanically graded biological nanocomposite material,” Acta Mater., vol. 53, no. 15, pp. 4281-4292, Sep. 2005.

[3] C. Peniche, W. Argüellers-Monal, and F. . Goycoolea, "Chitin and Chitosan: Major Sources, Properties and Applications," in Monomers, Polymers and Composites from Renewable Resources, First edit., vol. 1, M. N. Belgacem and A. Gandini, Eds. Elsevier, 2008, pp. 517-542.

[4] M. Rinaudo, "Chitin and chitosan: Properties and applications,” Prog. Polym. Sci., vol. 31, no. 7, pp. 603632, Jul. 2006.

[5] R. Jayakumar, D. Menon, K. Manzoor, S. V. Nair, and H. Tamura, "Biomedical applications of chitin and chitosan based nanomaterials-A short review," Carbohydr. Polym., vol. 82, no. 2, pp. 227-232, Sep. 2010.

[6] R. Jayakumar, M. Prabaharan, S. V. Nair, S. Tokura, H. Tamura, and N. Selvamurugan, "Novel carboxymethyl derivatives of chitin and chitosan materials and their biomedical applications," Prog. Mater. Sci., vol. 55, no. 7, pp. 675-709, Sep. 2010.

[7] S. C. Fernandes, C. S. Freire, A. J. Silvestre, C. Pascoal Neto, and A. Gandini, "Novel materials based on chitosan and cellulose,” Polym. Int., vol. 60, no. 6, pp. 875-882, Jun. 2011.

[8] J. Morgado et al., "Self-standing chitosan films as dielectrics in organic thin-film transistors," Express Polym. Lett., vol. 7, no. 12, pp. 960-965, 2013.

[9] S. Ifuku and H. Saimoto, "Chitin nanofibers: preparations, modifications, and applications," Nanoscale, vol. 4, no. 11, pp. 3308-3318, Jun. 2012.

[10] J. B. Zeng, Y. S. He, S. L. Li, and Y. Z. Wang, "Chitin whiskers: An overview," Biomacromolecules, vol. 
A.M. Salaberría1, R. Teruel-Juanes2, JD.Badia2,3, S.C.M. Fernandes1, V. Sáenz de Juano-Arbona2, J. Labidi1, A. Ribes-Greus. Influence of chitin nanocrystals on the dielectric behaviour and conductivity of chitosan-based bionanocomposites. Composites Science and Technology 2018; 167:323-330

13, no. 1 , pp. $1-11,2012$.

[11] B. Smitha, S. Sridhar, and A. A. Khan, "Polyelectrolyte complexes of chitosan and poly (acrylic acid) as proton exchange membranes for fuel cells," Macromolecules, vol. 37, no. 6, pp. 2233-2239, 2004.

[12] V. Vijayalekshmi and D. Khastgir, "Chitosan/partially sulfonated poly (vinylidene fluoride) blends as polymer electrolyte membranes for direct methanol fuel cell applications," Cellulose, vol. 25, no. 1, pp. $661-681,2018$.

[13] P.-C. Li et al., "Fabrication and characterization of chitosan nanoparticle-incorporated quaternized poly (vinyl alcohol) composite membranes as solid electrolytes for direct methanol alkaline fuel cells," Electrochim. Acta, vol. 187, pp. 616-628, 2016.

[14] M. Purwanto et al., "Biopolymer-based electrolyte membranes from chitosan incorporated with montmorillonite-crosslinked GPTMS for direct methanol fuel cells," RSC Adv., vol. 6, no. 3, pp. 23142322, 2016.

[15] H. Liu et al., "Chitosan/silica coated carbon nanotubes composite proton exchange membranes for fuel cell applications," Carbohydr. Polym., vol. 136, pp. 1379-1385, 2016.

[16] V. Vijayakumar and D. Khastgir, "Hybrid composite membranes of chitosan/sulfonated polyaniline/silica as polymer electrolyte membrane for fuel cells," Carbohydr. Polym., vol. 179, pp. 152-163, 2018.

[17] S. B. Aziz and Z. H. Z. Abidin, "Electrical and morphological analysis of chitosan:AgTf solid electrolyte," Mater. Chem. Phys., vol. 144, no. 3, pp. 280-286, 2014.

[18] S. B. Aziz and Z. H. Z. Abidin, "Ion-transport study in nanocomposite solid polymer electrolytes based on chitosan: Electrical and dielectric analysis," J. Appl. Polym. Sci., vol. 132, no. 15, 2015.

[19] J. D. Silvestre, J. de Brito, and M. D. Pinheiro, "Environmental impacts and benefits of the end-of-life of building materials - calculation rules, results and contribution to a 'cradle to cradle' life cycle," J. Clean. Prod., vol. 66, pp. 37-45, Mar. 2014.

[20] J. D. Badia, E. Strömberg, T. Kittikorn, M. Ek, S. Karlsson, and A. Ribes-Greus, "Relevant factors for the 
A.M. Salaberría1, R. Teruel-Juanes2, JD.Badia2,3, S.C.M. Fernandes1, V. Sáenz de Juano-Arbona2, J. Labidi1, A. Ribes-Greus. Influence of chitin nanocrystals on the dielectric behaviour and conductivity of chitosan-based bionanocomposites. Composites Science and Technology 2018; 167:323-330

eco-design of polylactide/sisal biocomposites to control biodegradation in soil in an end-of-life scenario," Polym. Degrad. Stab., vol. 143, pp. 9-19, Sep. 2017.

[21] A. Pangon, S. Saesoo, N. Saengkrit, U. Ruktanonchai, and V. Intasanta, "Hydroxyapatite-hybridized chitosan/chitin whisker bionanocomposite fibers for bone tissue engineering applications," Carbohydr. Polym., vol. 144, pp. 419-427, 2016.

[22] V. Rubentheren, T. A. Ward, C. Y. Chee, and C. K. Tang, "Processing and analysis of chitosan nanocomposites reinforced with chitin whiskers and tannic acid as a crosslinker," Carbohydr. Polym., vol. 115 , pp. 379-387, 2015.

[23] A. M. Salaberria, R. H. Diaz, J. Labidi, and S. C. M. Fernandes, "Preparing valuable renewable nanocomposite films based exclusively on oceanic biomass - Chitin nanofillers and chitosan," React. Funct. Polym., vol. 89, pp. 31-39, 2015.

[24] M. Mincea, A. Negrulescu, and V. Ostafe, "Preparation, modification, and applications of chitin nanowhiskers: A review," Rev. Adv. Mater. Sci., vol. 30, no. 3, pp. 225-242, 2012.

[25] A. A. Singh, J. Wei, N. Herrera, S. Geng, and K. Oksman, "Synergistic effect of chitin nanocrystals and orientations induced by solid-state drawing on PLA-based nanocomposite tapes," Compos. Sci. Technol., vol. 162, pp. 140-145, 2018.

[26] Z. Zou, C. Luo, B. Luo, W. Wen, M. Liu, and C. Zhou, "Synergistic reinforcing and toughening of poly(1lactide) composites with surface-modified MgO and chitin whiskers," Compos. Sci. Technol., vol. 133, pp. 128-135, 2016.

[27] N. Herrera et al., "Functionalized blown films of plasticized polylactic acid/chitin nanocomposite: Preparation and characterization," Mater. Des., vol. 92, pp. 846-852, Feb. 2016.

[28] A. M. Salaberria, J. Labidi, and S. C. M. Fernandes, "Chitin nanocrystals and nanofibers as nano-sized fillers into thermoplastic starch-based biocomposites processed by melt-mixing," Chem. Eng. J., vol. 256, pp. 356-364, 2014.

[29] S. Shankar, J. P. Reddy, J.-W. Rhim, and H.-Y. Kim, "Preparation, characterization, and antimicrobial $-29-$ 
A.M. Salaberría1, R. Teruel-Juanes2, JD.Badia2,3, S.C.M. Fernandes1, V. Sáenz de Juano-Arbona2, J. Labidi1, A. Ribes-Greus. Influence of chitin nanocrystals on the dielectric behaviour and conductivity of chitosan-based bionanocomposites. Composites Science and Technology 2018; 167:323-330

activity of chitin nanofibrils reinforced carrageenan nanocomposite films," Carbohydr. Polym., vol. 117, pp. 468-475, Mar. 2015.

[30] A. J. Uddin, M. Fujie, S. Sembo, and Y. Gotoh, "Outstanding reinforcing effect of highly oriented chitin whiskers in PVA nanocomposites," Carbohydr. Polym., vol. 87, no. 1, pp. 799-805, Jan. 2012.

[31] J. Ma and Y. Sahai, "Chitosan biopolymer for fuel cell applications," Carbohydr. Polym., vol. 92, no. 2, pp. 955-975, 2013.

[32] H. Ahmad, S. K. Kamarudin, U. A. Hasran, and W. R. W. Daud, "Overview of hybrid membranes for direct-methanol fuel-cell applications," Int. J. Hydrogen Energy, vol. 35, no. 5, pp. 2160-2175, Mar. 2010.

[33] M. T. Viciosa, M. Dionisio, R. M. Silva, R. L. Reis, and J. F. Mano, "Molecular motions in chitosan studied by dielectric relaxation spectroscopy,” Biomacromolecules, vol. 5, no. 5, pp. 2073-2078, 2004.

[34] J. B. González-Campos et al., "Dielectric relaxations of chitosan: The effect of water on the $\alpha$-relaxation and the glass transition temperature," J. Polym. Sci. Part B Polym. Phys., vol. 47, no. 22, pp. 2259-2271, Nov. 2009.

[35] J. D. Badia et al., "Water absorption and hydrothermal performance of PHBV/sisal biocomposites," Polym. Degrad. Stab., 2014.

[36] O. Gil-Castell et al., "Impact of hydrothermal ageing on the thermal stability, morphology and viscoelastic performance of PLA/sisal biocomposites," Polym. Degrad. Stab., 2016.

[37] J. C. Maxwell, "Electricity and Magnetism, vol. 1, Clarendon.” Oxford, 1892.

[38] K. W. Wagner, “The after effect in dielectrics," Arch. Electrotech, vol. 2, no. 378, p. e394, 1914.

[39] R. W. Sillars, "The properties of a dielectric containing semiconducting particles of various shapes," Inst. Electr. Eng. Wirel. Sect. Inst., vol. 12, no. 35, pp. 139-155, 1937.

[40] Z. Lu, E. Manias, and D. D. Macdonald, "Dielectric Relaxation Spectroscopy Studies on Water-Saturated Nafion 117 Membrane," in In Proceedings of the Electrochemical Society 204th National Meeting, 2003. 
A.M. Salaberría1, R. Teruel-Juanes2, JD.Badia2,3, S.C.M. Fernandes1, V. Sáenz de Juano-Arbona2, J. Labidi1, A. Ribes-Greus. Influence of chitin nanocrystals on the dielectric behaviour and conductivity of chitosan-based bionanocomposites. Composites Science and Technology 2018; 167:323-330

[41] G. W. Gross and J. Johnson, “The Layered Capacitor Method for Dielectric Bridge Measurements. Data Analysis and Interpretation of Fluoride Doped ICE.," IEEE Trans. Electr. Insul., no. 5, pp. 485-497, 1983.

[42] A. R. Von Hippel, "Dielectrics and waves," 1954.

[43] S. A. Cruz and M. Zanin, "Dielectric strength of the blends of virgin and recycled HDPE," J. Appl. Polym. Sci., vol. 91, no. 3, pp. 1730-1735, 2004.

[44] W. Zheng and S.-C. Wong, "Electrical conductivity and dielectric properties of PMMA/expanded graphite composites," Compos. Sci. Technol., vol. 63, no. 2, pp. 225-235, 2003.

[45] S. Singha and M. J. Thomas, "Dielectric properties of epoxy nanocomposites," IEEE Trans. Dielectr. Electr. Insul., vol. 15, no. 1, pp. 12-23, 2008.

[46] J. D. Badia et al., "Dielectric spectroscopy of reprocessed polylactide," Polym. Degrad. Stab., vol. 107, pp. 21-27, Sep. 2014.

[47] J. D. Badia et al., "Effect of sisal and hydrothermal ageing on the dielectric behaviour of polylactide/sisal biocomposites," Compos. Sci. Technol., vol. 149, pp. 1-10, 2017.

[48] S. Kumar-Krishnan et al., "Novel gigahertz frequency dielectric relaxations in chitosan films," Soft Matter, vol. 10, no. 43, pp. 8673-8684, 2014.

[49] J. Einfeldt, D. Meißner, and A. Kwasniewski, "Molecular interpretation of the main relaxations found ID dielectric spectra of cellulose -- experimental arguments," Cellulose, vol. 11, no. 2, pp. 137-150, 2004.

[50] J.-D. Badia, L. Santonja-Blasco, A. Martínez-Felipe, and A. Ribes-Greus, Dynamic Mechanical Thermal Analysis of Polymer Blends. 2015.

[51] J. M. Charlesworth, "Deconvolution of overlapping relaxations in dynamic mechanical spectra," J. Mater. Sci., vol. 28, no. 2, pp. 399-404, 1993.

[52] S. Havriliak and S. Negami, "A complex plane analysis of $\alpha$-dispersions in some polymer systems," in Journal of Polymer Science Part C: Polymer Symposia, 1966, vol. 14, no. 1, pp. 99-117. 
A.M. Salaberría1, R. Teruel-Juanes2, JD.Badia2,3, S.C.M. Fernandes1, V. Sáenz de Juano-Arbona2, J. Labidi1, A. Ribes-Greus. Influence of chitin nanocrystals on the dielectric behaviour and conductivity of chitosan-based bionanocomposites. Composites Science and Technology 2018; 167:323-330

[53] S. Havriliak and S. Negami, "A complex plane representation of dielectric and mechanical relaxation processes in some polymers," Polymer (Guildf)., vol. 8, pp. 161-210, 1967.

[54] A. Martínez-Felipe, L. Santonja-Blasco, J. D. Badia, C. T. Imrie, and A. Ribes-Greus, “Characterization of functionalized side-chain liquid crystal methacrylates containing nonmesogenic units by dielectric spectroscopy," Ind. Eng. Chem. Res., 2013.

[55] H. Eyring, "The activated complex in chemical reactions," J. Chem. Phys., vol. 3, no. 2, pp. 107-115, 1935.

[56] J. Heijboer, "Molecular origin of relaxations in polymers," Ann. N. Y. Acad. Sci., vol. 279, no. 1, pp. 104116, 1976.

[57] J. Heijboer, "Secondary loss peaks in glassy amorphous polymers," in Molecular basis of transitions and relaxations, D. J. Meier, Ed. CRC Press, 1978, p. 429.

[58] O. Gil-Castell et al., "Hydrothermal ageing of polylactide/sisal biocomposites. Studies of water absorption behaviour and Physico-Chemical performance," Polym. Degrad. Stab., 2014.

[59] M. Pizzoli, G. Ceccorulli, and M. Scandola, "Molecular motions of chitosan in the solid state," Carbohydr. Res., vol. 222, pp. 205-213, 1991.

[60] J. Einfeldt, D. Meißner, and A. Kwasniewski, "Polymerdynamics of cellulose and other polysaccharides in solid state-secondary dielectric relaxation processes," Prog. Polym. Sci., vol. 26, no. 9, pp. 1419-1472, 2001.

[61] Z. Montiel-González, G. Luna-Bárcenas, and A. Mendoza-Galván, "Thermal behaviour of chitosan and chitin thin films studied by spectroscopic ellipsometry," Phys. status solidi, vol. 5, no. 5, pp. 1434-1437, May 2008

[62] A. Nogales, T. A. Ezquerra, D. R. Rueda, F. Martinez, and J. Retuert, "Influence of water on the dielectric behaviour of chitosan films," Colloid Polym. Sci., vol. 275, no. 5, pp. 419-425, 1997.

[63] H. Vogel, "The temperature dependence law of the viscosity of fluids," Phys. Z, vol. 22, pp. 645-646, 
A.M. Salaberría1, R. Teruel-Juanes2, JD.Badia2,3, S.C.M. Fernandes1, V. Sáenz de Juano-Arbona2, J. Labidi1, A. Ribes-Greus. Influence of chitin nanocrystals on the dielectric behaviour and conductivity of chitosan-based bionanocomposites. Composites Science and Technology 2018; 167:323-330

1921.

[64] G. S. Fulcher, “Analysis of recent measurements of the viscosity of glasses," J. Am. Ceram. Soc., vol. 75, no. 5, pp. 1043-1055, 1992.

[65] E. Zuza, J. M. Ugartemendia, A. Lopez, E. Meaurio, A. Lejardi, and J. R. Sarasua, “Glass transition behavior and dynamic fragility in polylactides containing mobile and rigid amorphous fractions," Polymer (Guildf)., vol. 49, no. 20, pp. 4427-4432, 2008.

[66] K. Kunal, C. G. Robertson, S. Pawlus, S. F. Hahn, and A. P. Sokolov, "Role of chemical structure in fragility of polymers: A qualitative picture,” Macromolecules, vol. 41, no. 19, pp. 7232-7238, 2008.

[67] A. K. Doolittle, "Studies in Newtonian Flow. II. The Dependence of the Viscosity of Liquids on FreeSpace," J. Appl. Phys., vol. 22, no. 12, p. 1471, 1951.

[68] A. K. Doolittle, "Studies in Newtonian Flow. III. The Dependence of the Viscosity of Liquids on Molecular Weight and Free Space (in Homologous Series),” J. Appl. Phys., vol. 23, no. 2, p. 236, 1952.

[69] J. D. Ferry, Viscoelastic properties of polymers. John Wiley \& Sons, 1980.

[70] Y. Dong, Y. Ruan, H. Wang, Y. Zhao, and D. Bi, "Studies on glass transition temperature of chitosan with four techniques,” J. Appl. Polym. Sci., vol. 93, no. 4, pp. 1553-1558, 2004.

[71] J. B. González-Campos et al., "Relaxations in chitin: evidence for a glass transition," J. Polym. Sci. Part B Polym. Phys., vol. 47, no. 9, pp. 932-943, 2009.

[72] A. K. Jonscher, "Dielectric relaxation in solids," J. Phys. D. Appl. Phys., vol. 32, no. 14, p. R57, 1999.

[73] A. K. Jonscher, “The ‘universal'dielectric response,” Nature, vol. 267, no. 5613, p. 673, 1977.

[74] J. C. Dyre, "Some remarks on ac conduction in disordered solids," J. Non. Cryst. Solids, vol. 135, no. 2, pp. 219-226, 1991. 
A.M. Salaberría1, R. Teruel-Juanes2, JD.Badia2,3, S.C.M. Fernandes1, V. Sáenz de Juano-Arbona2, J. Labidi1, A. Ribes-Greus. Influence of chitin nanocrystals on the dielectric behaviour and conductivity of chitosan-based bionanocomposites. Composites Science and Technology $2018 ; 167: 323-330$

\section{ANNEX. OPEN ACCESS POLICIES}

Buscar - Políticas de copyright de las editoriales y autoarchivo

Se ha encontrado una revista que coincide con los criterios de búsqueda:.: composites science and technology

\begin{tabular}{|c|c|}
\hline Revista: & Composites Science and Technology. (ISSN: 0266-3538, ESSN: 1879-1050) \\
\hline ROMEO: & This is a RoMEO green journal \\
\hline OA de pago: & Esta revista dispone de una opción de acceso abierto de pago \\
\hline Pre-print del autor: & $\checkmark$ el autor puede archivar la versión pre-print (ie la versión previa a la revisión por pares) \\
\hline Post-print del autor: & $\checkmark$ el autor puede archivar la versión post-print (ie la versión final posterior a la revisión por pares) \\
\hline Versión de editor/PDF: & $\mathbf{X}$ el autor no puede archivar la versión del editor/PDF \\
\hline Condiciones generales: & 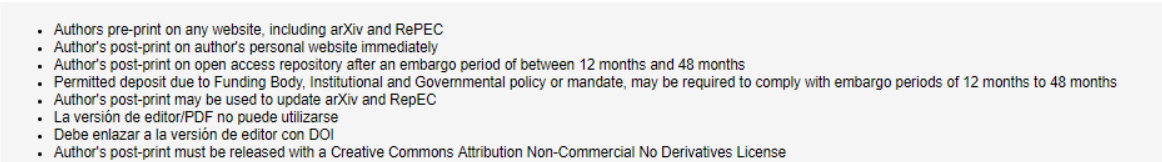 \\
\hline OA mandatorio: & (Esperando información) \\
\hline Open Access de pago: & Qoen Access \\
\hline Notas: & . Publisher last reviewed on 03/06/2015 \\
\hline Copyright: & $\begin{array}{l}\text { Unleashing the power of academic sharing - Sharing Policy - Sharing and Hosting Policy FAQ - Green open access - Journal Embargo Period List (pdf) - Journal Embargo List for UK } \\
\text { Authors - }- \text { Altaching a USer License (pdf) - Funding Body Agreements }\end{array}$ \\
\hline Actualizado: & 01-May-2015 - $\underline{\text { Sugiera una actualización de este registro }}$ \\
\hline Enlace a esta página: & hittp://wwww.sherpa.ac.ukromeo/issn/0266-3538/es/ \\
\hline Publicado por: & Elsevier - Green Policies in RoMEO \\
\hline
\end{tabular}

